\title{
Association Between Heavy Metals and Colon Cancer: An Ecological Study Based on Geographical Information Systems in Northeastern Iran
}

\author{
Behzad Kiani \\ Mashhad University of Medical Sciences \\ Fatemeh Hashemi Amin \\ Mashhad University of Medical Sciences \\ Nasser Bagheri \\ Australian National University \\ Ali Akbar Mohammadi \\ Neyshabur University of Medical Sciences \\ Mahmood Yousefi \\ Iran University of Medical Sciences: Tehran University of Medical Sciences \\ Hossein Faraji \\ Hamadan University of Medical Sciences School of Public Health \\ Gholamreza Roshandel \\ Golestan University of Medical Sciences and Health Services \\ Somayeh Beirami \\ Golestan University of Medical Sciences and Health Services \\ Hadi Rahimzadeh \\ Golestan University of Medical Sciences and Health Services \\ Benyamin Hoseini ( $\sim$ Hoseinib1@nums.ac.ir) \\ Mashhad University of Medical Sciences https://orcid.org/0000-0002-0355-6181
}

\section{Research}

Keywords: Heavy metals, Colon cancer, Geographical information systems, Regression model, Ordinary least square

Posted Date: November 20th, 2020

DOI: https://doi.org/10.21203/rs.3.rs-111177/v1

License: @ (i) This work is licensed under a Creative Commons Attribution 4.0 International License. Read Full License 


\section{Abstract}

\section{Background}

Exposure to environmental pollutants such as heavy metals has been introduced as a possible contributor to increasing the risk of colon cancer. We aim to explore the associations between heavy metals and the age-standardized incidence rate (ASR) colon cancer in Northeastern Iran.

Methods

Cancer data were drawn from the population-based cancer registry of Golestan province, Northeastern Iran. The heavy metals' samples were collected from 69 rice milling plants in the study area. Then, the concentration level of seven heavy metals, including Cadmium, Nickel, Cobalt, Copper, Selenium, Lead, and Zink was measured. The Kriging algorithm was used to interpolate the heavy metals' concentration on the surface of the study area. The exploratory regression analysis was conducted to build the ordinary least squares (OLS) models on every possible combination of the candidate explanatory variables. Finally, the best OLS models were chosen to show the effect of heavy metals on colon cancer.

Results

Generally, heavy metals were higher in central part of the province. The analyses showed that the high concentration of Cobalt was associated with the high ASR of colon cancer in men. In contrast, the Selenium concentration was higher in areas with lower ASR of colon cancer in men. A significant regression equation for men colon cancer was found $(F(4,137)=38.304, P<.000)$ with an adjusted $R^{2}$ of 0.77 . The predicted ASR of men colon cancer was -58.3581 with the coefficients for Cobalt $=120.329780$; Cadmium= 80.603505; Selenium $=-6.069037$; Nickel $=-3.086802$; and Zink $=-0.405843$. The effect of Copper and Lead on men colon cancer was not significant. We did not find a significant model for women colon cancer.

\section{Conclusion}

There may be a possible negative correlation between selenium concentration and lower risk of colon cancer in men. Furthermore, the higher cobalt concentration may be related to an increased risk of men colon cancer.

\section{Introduction}

Colon cancer is ranked the third most frequent malignancy all over the world, and the fourth most common cancer in Iran [1, 2]. According to Global Cancer Observatory statistics, the colon cancer incidence and mortality rate are increasing rapidly. As a result, it is estimated that around 18 million new cases occur, and 9 million people die due to colon cancer worldwide annually [3]. These figures may be skewed in the direction of a higher percentage in low-income countries. Scientific literature revealed that many factors can be involved in the development of colon cancer [4-9]. These factors are mainly categorized into modifiable (obesity, physical inactivity, diet, smoking, and access to medical services) $[7,8]$ and non-modifiable ones (age, gender, family history and genetics) $[4-6,9]$. Furthermore, exposure to environmental pollutants and heavy metals can be a potential contributor to risk of cancer development [10-13].

Previous studies highlighted the association between heavy metals and some cancers [14-18]. Adimalla et al. (2019) [14] investigated the association between heavy metals in soil and human health risk for adults and children in India during 2001-2019, and found high concentration of some heavy metals such as arsenic and chromium could be potentially associated with increased cancer risk for both adults and children. Jemal et al. (2002) assessed the association between blood lead level and all cancer mortality in the United States using data from the National Health and Nutrition Examination Survey (NHANES) II Mortality Study, 1992, and reported no significant association between blood lead levels in the range of NHANES II and increased risk of cancer mortality [16]. Fei et al. (2018) [15] assessed the association between heavy metals contamination and the spatial distribution of stomach cancer incidence in Hangzhou from 2009 to 2012. They found the joint contamination of multiple heavy metals was significantly associated with stomach cancer risk, although the heavy metals did not associated with the distribution of stomach cancer incidence when considering separately [15]. Sohrabi et al. (2018) [17] assessed the association of heavy metals and colorectal cancer in the city of Tehran between March 2015 and February 2016. This cross-sectional study of tissue levels of trace 
elements revealed that the heavy metals might affect developing colorectal cancer. A meta-analysis by Qiao et al. (2013) investigated the associations between intakes of heme iron and zinc and colorectal cancer incidence, suggesting a significant inverse dose-response association of zinc intake with risk of colorectal cancer [18].

Heavy metals exist in water, air, soil, and food. Previous studies $[19,20]$ have measured the levels of heavy metals in rice, estimated potential cancer risks, and highlighted the association between heavy metals concentration in rice and cancers risks. Rice is mostly consumed by Iranian people as the main meal for both lunch and dinner. Kukusamude et al. (2020) [19] have measured heavy metals including chromium, zinc, nickel, copper, manganese, cobalt, arsenic, and cadmium in 55 Thai local rice, and assessed the potential impact on Thai population by means of probabilistic approach. They found that the maximum cancer probabilities over the lifetime consumption of Thai local rice were in the range of 5 in 10,000 to 3 in 1000 chances in developing cancer. Al-Saleh et al. (2017) [20] measured the levels of heavy metals including lead, cadmium, methylmercury and arsenic in 37 brands of imported rice commonly consumed in Saudi Arabia, and estimated their potential health risks to residents by three indices: hazard quotient, hazard index and cancer risk. They found that long-term consumption of rice contaminated with heavy metals, particularly arsenic, can pose potential cancer risks to the local population. Rahimzadeh et al. (2017) measured the level of heavy metals in rice harvested in the Golestan Province, Iran, and assessed the association between heavy metals and esophagus cancer incidence. They revealed that heavy metals may act as possible risk factors for esophagus cancer in this Province. To our knowledge, there is no study in the Golestan province with regards to the effect of amount of heavy metals in rice on colon cancer.

People who are living close to each other may have more similar exposure to heavy metals. Accordingly, spatial analyses could help scientists to explore how heavy metals and colon cancer incidence rates are associated. Such studies are conducted by Geographical Information Systems (GIS), which consider the geographical distribution patterns of heavy metals to investigate their association with human health. Ordinary least square (OLS) is a practical approach in GIS for estimating the relationship between a response variable and explanatory variables [21]. Goshayeshi et al. (2019) [22] used OLS method in North-eastern Iran to explore the relationship between colorectal cancer incidence and some explanatory variables, including Body Mass Index, Daily fiber intake, red meat consumption, and people older than 50 years old. They found that all the explanatory variables were associated with colorectal cancer incidence except the red meat consumption. Therefore, investigation of the association of environmental factors and the incidence of colon cancer is important in spatial epidemiology. Further, spatial analyses of the association of heavy metals and incident of colon cancer will generate new knowledge on spatial variations of these relationships. This study aims to assess the association between the level of heavy metals in rice and the age-standardized incidence rate (ASR) of colon cancer in the Golestan province, Iran.

\section{Methods}

Setting: This study was conducted in 11 counties of the province of Golestan in Iran in 2018 (Figure 1). It covers an area of 20,367 with a population of 1,868,819 people. The study area was shown in figure 1, and the points represent 69 milling factories included in this research.

Figure 1: The location of the study area with the distribution of milling factories in 2018

Data sources: We used two different data sources; cancer registry to extract colon cancer events and calculate age-standardized rate (ASR) of colon cancer. The second data was the heavy metals in rice samples analyzed by laboratory including Zink (Zn), Cadmium $(\mathrm{Cd})$, Lead (Pb), Copper (Cu), Nickel (Ni), Cobalt (Co), and Selenium (Se). We used the ASR of colon cancer as the dependent variable for statistical modelling.

Sampling: The sample size was estimated based on a study that was conducted by Zazouli et al. (2008) [23] in cultured rice in the province of Mazandaran, which is similar to Golestan climate. As lead conformed a large proportion of heavy metals, the sample size was calculated based on lead. Confidence interval level $(a=0.05)$ and error rate $(d)$ were assumed .05\%, using formula 1.

$$
\text { 1) } \quad N=\left(\mathrm{z}_{(1-\alpha / 2)}^{2} * \sigma^{2}\right) / d^{2}
$$

where $z$ is value of normal variable with confidence level of , is the standard deviation of the amount of lead, and $d$ is error rate. 
The required sample size was determined 62. Considering adequate allocation of the area under cultivation, for some counties sample size was estimated 1 or 2 , which was not interpretable. As a result, at least 4 cases were considered for each county and ultimately, a total of 69 samples were investigated in this study. The number of samples for every county in the study area is shown in Table 1.

Table 1. The number of samples in the study area

Considering that after harvest, rice shawl will be delivered to milling factories to subsequent operations, samples were drawn from milling factories in each county. In cases that the number of milling factory was more than the number of samples, one sample was obtained from each factory, and then samples were taken from a mixture. The mixture was prepared from samples taken from each factory by mixing them together and then we took a $0.5 \mathrm{~kg}$ sample from the mixture for investigation. The plastic bags were transported to the environmental chemistry laboratory of the school of public health and kept in the refrigerator till analyses to be conducted. In investigation step, the concentration of seven heavy metals in samples was measured including Zink (Zn), Cadmium (Cd), Lead (Pb), Copper (Cu), Nickel (Ni), Cobalt (Co), and Selenium (Se).

\section{Spatial Analysis:}

Interpolation: Kriging is an interpolation algorithm that predicts the unobserved values based on known points values [24]. In this study, the Kriging method was used to spatially interpolate the amount of heavy metals in the study area, considering 12 near points. Kriging is most appropriate when there is a spatially correlated distance or directional bias in the data. Its result is a raster dataset in which every pixel shows the amount of one of the heavy metals in that particular area estimated by 12 near sampled points.

We converted the kriging results into vector polygon layers by creating a point layer of pixels and then spatially joined the points to the digital layer of Golestan counties using ArcGIS 10.1. The average of each heavy metal values was calculated for each county polygon.

Exploratory Regression mining: we used the exploratory regression analysis approach to develop several regression models. Explanatory variables were heavy metals, and the dependent variable was ASR of men and women colon cancer. We used ArcGIS 10.5 to conduct the exploratory regression analyses. This tool runs many OLS models using all possible combinations for a list of independent variables and evaluates which model better fits. The six items addressed in assessing an appropriate regression model are [25] :

1- Expected sign for each coefficient:

The sign of each coefficient should be consistent with the scientific literature. For example, in recent literature lead has had a positive correlation with cancer occurrence and we expect to find a consistent result in our study.

2- Lack of redundancy among dependent variables:

Variance inflation factor (VIF) should be smaller than about 7.5 for any variables otherwise collinearity will be between some exposure variables.

3- Significance of coefficients:

Probability and Robust Probability in the result should be checked to assess if coefficients are statistically significant.

4- Normal distribution of residuals:

For this purpose, Jarque-Bera test should not be statistically significant and sum of residuals should be zero with a SD of 1 .

5- Strong adjusted R-squared value:

The adjusted R-square value should be at least more than 0.5 .

Page $4 / 14$ 
6- Lack of spatial autocorrelation among OLS residuals:

Global Moran's index can be used to measure spatial autocorrelation.

\section{Results}

Overall, there was 1184 colon cancer cases (656 Male vs. 528 Female) in Golestan province, Iran in 2018. ASR ranged between 3.1 and 18.6 for males among study areas, as Ramian had the lowest rate and Gorgan had the highest one. It ranged between 1.4 and 14 for females, as Minodasht had the lowest rate and Gorgan had the highest one.

The average concentration of heavy metals ranged from 20.33 to $56.14(\mathrm{mg} / \mathrm{kg})$ for $Z \mathrm{n}, 0$ to $0.101(\mathrm{mg} / \mathrm{kg})$ for Cd, 0 to 2.23 (mg/kg) for $\mathrm{Pb}, 0.76$ to 10.17 (mg/kg) for $\mathrm{Cu}, 0.64$ to $4.42(\mathrm{mg} / \mathrm{kg})$ for Ni, 0 to $0.12(\mathrm{mg} / \mathrm{kg})$ for Co, and 0.49 to $4.76(\mathrm{mg} / \mathrm{kg})$ for Se. Gonbad had the highest average concentration of $\mathrm{Cd}, \mathrm{Pb}, \mathrm{Ni}$, and $\mathrm{Co}$. Table 2 shows the average concentration of heavy metals in the study areas.

The geographical distribution of the colon cancer ASR is shown in Figure 2. Gorgan County demonstrates the highest ASR, while Azadshahr and Ramian counties are ranked as the lowest ASR. Figure 3 shows the spatial distribution of explanatory variables used to build the regression model to predict the ASR colon cancer as the dependent variable. The figure shows a high level of heavy metals concentration in the central part of the study area. However, Nickel and Selenium had a higher concentration in the NorthEast of the study area.

The exploratory regression model was run for men and women separately, considering seven independent variables. Among these variables, Selenium and Cobalt were significant in $20.31 \%$ and $12.5 \%$ of the created models for men colon cancer, respectively. However, lead was not significant in any model. Only Selenium and Cobalt had a clear direction in all models. In other words, Selenium had an inverse association with ASR of colon cancer in men, while Cobalt had a positive association with the dependent variable in all models. Table 3 and 4 show the sign and significance level of the independent variables in all regression models for men and women colon cancer, respectively.

Two models for men were identified using the Exploratory Regression, which fit all the six requirements mentioned in the method section. As table 5 shows, their adjusted values were above 0.7 , which illustrated the high performance of the models, and they explored five significant variables ( $P$ value $<0.05$ ). The model 1 showed a better fit model with higher adjusted of 0.77 and lower Akaike's Information Criterion of 89.14 for men colon cancer (Table 5).

None of models met all six requirements mentioned in the method section for women for colon cancer. However, table 6 shows the two best models with the highest adjusted and lowest AICc.

\section{Discussion}

To our knowledge, this is the first study in Golestan province, Iran to identify spatial patterns of ASR of colon cancer. The main aim of the study was to measure the association of heavy metals with colon cancer incidence. While a high concentration of the heavy metals' distribution was observed in central part of the study area, Nickel and Selenium had a higher concentration in the North-East of the study area. Gorgan and Gonbad Counties had the highest ASR of the colon cancer. Our findings showed that Cobalt was positively associated with ASR of colon cancer in men, while higher Selenium was associated with lower ASR of colon cancer in this group. However, the study did not find any significant association between heavy metals and ASR of colon cancer when the analyses were performed for women group. These findings are in line with previous studies [26-30].

A study by Rahimzadeh et al. [31] in Golestan province reported that the selenium concentration in high-risk areas of esophageal cancer was significantly higher than in low-risk areas, while, our study revealed reverse relationship for colon cancer in these areas, at least, for men group. Our study findings were in line with the findings of two previous meta-analyses [26, 27], which reported a protective effect of selenium for colorectal adenomas. Another study [30] highlighted that the lower concentrations of selenium with the threshold of $55 \mu \mathrm{g} / \mathrm{l}$ and $65 \mu \mathrm{g} / \mathrm{l}$ for Poland and Estonia, respectively, were associated with a higher risk of colorectal cancer. According to Fernandez-Banares et al. study [32], the high level of Selenium $(\geq 82.11 \mu \mathrm{g} / \mathrm{L})$ decreases the risk of colorectal adenomas for cases aged $<60$ years. Although they found no significant association for cases aged $\geq 60$ years, another study [28] 
reported a low risk of colorectal adenomas for cases aged $\geq 67$ years with a high level of Selenium. Our study revealed no significant association between Selenium concentrations and colon cancer in women group. Peters et al. [28] reported as same as our findings for men but not for women. It is recommended that the impact of age and gender need to be further considered within the association between selenium concentrations and risk of colon cancers which remains for future studies.

As a part of vitamin B12, cobalt is beneficial for human health. However, excessive concentration of cobalt may damage human health [33]. Previous studies investigated the association between exposure to cobalt and cancer incidence and reported controversial findings [34-36]. A study by Turkdogan et.al [34] reported that heavy metals such as cobalt could be related to the high prevalence of upper gastrointestinal cancer rates, and another study [35] reported exposure to cobalt might increase the risk of lung cancer. On the other hand, Sauni et al. [36] suggested that occupational-exposure to cobalt may not be associated with increased overall cancer risk. Our study revealed that cobalt is significantly associated with colon cancer incidence in men. Contaminated soil and water may be the source of environmental exposure to heavy metal [37]. Heavy-metal contamination of the agricultural soil and water was previously reported in some areas of Iran [38]. Further studies are needed to find the source of the high level of cobalt concentration in Golestan, especially in the central region of this province. Further, we need to conduct future studies to assess the association between exposure to cobalt and colon cancer incidence at the individual level.

Although Nickel and Selenium had a higher concentration in the North-East of the study area. There is no specific industry in these areas. The high level of these two metals' concentration in this area may depend on the soil's mineral type.

Environmental factors such as heavy metals [39-42] may explain spatial variation in colon cancer pattern. Lead, for example, is becoming a major health concern, and exposure to it may enhance the risk of cancer [39, 40]. A study by Halimi et al. [43] performed in Hamedan province, Iran, strongly brought forth the hypothesis that exposure to heavy metals, especially lead, might result in a high incidence of colorectal cancer. Although our study reinforced their hypothesis regarding some heavy metals such as selenium and cobalt, the results could not confirm that exposure to lead may enhance the risk of colon cancer.

Genetically inherited autosomal disorders such as lynch syndrome increase the risk of colon cancer [44], and it is estimated $10-14 \%$ of cases to be at high risk of lynch syndrome-associated colon cancers in Iran [5, 6, 45-47]. However, we found no study addressed this subject in Golestan province. As the high ASR of colon cancer in some regions of the study area such as Gonbad and Gorgan may be due to a high prevalence of lynch syndrome, the screening for this disorder among colon cancers is strongly suggested for future research.

\section{Limitation(s):}

The population census in Iran is carried out every five years, so we used census data for 2010 and 2015 for this research because we did not have an annual census data.

\section{Conclusion}

The inverse association between higher selenium concentration and risk of colon cancer reinforces previous findings indicating that higher selenium concentration may decrease the risk of colon cancer in men. Also, the study revealed that higher cobalt concentration might be related to an increased risk of colon cancer. However, our study was ecological research, further studies are needed to confirm these findings.

\section{Abbreviations}

OLS model, Ordinary Least Squares model; AdjR2, Adjusted R-Squared; AICc, Akaike's Information Criterion; JB, Jarque-Bera p-value; K(BP), Koenker's studentized Breusch-Pagan p-value; VIF Maximum, Variance Inflation Factor; SA Global Moran's I p-value, a measure of residual spatial autocorrelation; Model Variable direction (+/-); Model Variable significance $(*=0.10, * \star=0.05, * \star \star=$ 0.01).

\section{Declarations}


The study has only used aggregated data drawn from the population-based cancer registry of Golestan province, Iran and did not involve human subjects.

\section{Consent for publication.}

Not applicable.

\section{Availability of data and materials.}

Data will be provided upon request with the permission of the corresponding authors.

\section{Competing interests.}

The authors declare that they have no competing interests.

\section{Funding.}

This study was supported by Golestan University of Medical Sciences (grant number of 90-10-1-30209).

\section{Authors' contributions.}

$\mathrm{BH}, \mathrm{BK}$, and $\mathrm{HR}$ designed the study design. All authors contributed in data gathering and interpretation of the results. $\mathrm{BK}, \mathrm{BH}$, and FHA performed analyses and wrote the first draft of the manuscript. NB edited final version of the manuscript. All authors read, commented and approved the final manuscript.

\section{Acknowledgment.}

We would like to thank Golestan University of Medical Sciences for its supports.

\section{References}

1. West, N.P., Complete mesocolic excision for colon cancer: is now the time for a change in practice? The Lancet Oncology, 2019. 20(11): p. 1474-1476.

2. Setareh, S., et al., Using data mining for survival prediction in patients with colon cancer. Iranian Journal of Epidemiology, 2018. 14(1): p. 19-29.

3. Ferlay, J., et al., Estimating the global cancer incidence and mortality in 2018: GLOBOCAN sources and methods. International journal of cancer, 2019. 144(8): p. 1941-1953.

4. Chow, W.H., S.S. Devesa, and W.J. Blot, Colon cancer incidence: recent trends in the United States. Cancer Causes Control, 1991. 2(6): p. 419-25.

5. Goshayeshi, L., et al., Screening for Lynch Syndrome in Cases with Colorectal Carcinoma from Mashhad. Archives of Iranian Medicine (AIM), 2017. 20(6).

6. Goshayeshi L, Ghaffarzadegan K, and et a. Khooei A, Prevalence and clinicopathological characteristics of mismatch repairdeficient colorectal carcinoma in early onset cases as compared with lateonset cases: a retrospective cross-sectional study in Northeastern Iran. BMJ Open, 2018.

7. Frezza, E.E., M.S. Wachtel, and M. Chiriva-Internati, Influence of obesity on the risk of developing colon cancer. Gut, 2006. 55(2): p. 285-91.

8. Tarasiuk, A., P. Mosinska, and J. Fichna, The mechanisms linking obesity to colon cancer: An overview. Obes Res Clin Pract, 2018. 12(3): p. 251-259.

9. Khorram, M.R., et al., Prevalence of Mismatch Repair-Deficient Colorectal Adenoma/Polyp in Early-Onset, Advanced Cases: a Cross-Sectional Study Based on Iranian Hereditary Colorectal Cancer Registry. J Gastrointest Cancer, 2020. 
10. Antwi, S.O., et al., Exposure to environmental chemicals and heavy metals, and risk of pancreatic cancer. Cancer Causes Control, 2015. 26(11): p. 1583-91.

11. Lim, J.T., et al., Association between serum heavy metals and prostate cancer risk - A multiple metal analysis. Environ Int, 2019. 132: p. 105109.

12. Tang, W.R., et al., Development of esophageal cancer in Chaoshan region, China: association with environmental, genetic and cultural factors. Int J Hyg Environ Health, 2015. 218(1): p. 12-8.

13. Nawrot, T.S., et al., Association of total cancer and lung cancer with environmental exposure to cadmium: the meta-analytical evidence. Cancer Causes Control, 2015. 26(9): p. 1281-8.

14. Adimalla, N., Heavy metals pollution assessment and its associated human health risk evaluation of urban soils from Indian cities: a review. Environmental geochemistry and health, 2019: p. 1-18.

15. Fei, X., et al., The association between heavy metal soil pollution and stomach cancer: a case study in Hangzhou City, China. Environmental geochemistry and health, 2018. 40(6): p. 2481-2490.

16. Jemal, A., et al., The association of blood lead level and cancer mortality among whites in the United States. Environ Health Perspect, 2002. 110(4): p. 325-9.

17. Sohrabi, M., et al., Trace element and heavy metal levels in colorectal cancer: comparison between cancerous and noncancerous tissues. Biological trace element research, 2018. 183(1): p. 1-8.

18. Qiao, L. and Y. Feng, Intakes of heme iron and zinc and colorectal cancer incidence: a meta-analysis of prospective studies. Cancer Causes Control, 2013. 24(6): p. 1175-83.

19. Kukusamude, C., et al., Heavy metals and probabilistic risk assessment via rice consumption in Thailand. Food Chem, 2020. 334: p. 127402.

20. Al-Saleh, I. and M. Abduljabbar, Heavy metals (lead, cadmium, methylmercury, arsenic) in commonly imported rice grains (Oryza sativa) sold in Saudi Arabia and their potential health risk. Int J Hyg Environ Health, 2017. 220(7): p. 1168-1178.

21. Lemenkova, P., Testing Linear Regressions by StatsModel Library of Python for Oceanological Data Interpretation. Aquatic Sciences and Engineering, 2019. 34(2): p. 51-60.

22. Goshayeshi, L., et al., Colorectal cancer risk factors in north-eastern Iran: A retrospective cross-sectional study based on geographical information systems, spatial autocorrelation and regression analysis. Geospat Health, 2019. 14(2).

23. Zazouli, M.A., et al., Investigation of cadmium and lead contents in Iranian rice cultivated in Babol region. Asian Journal of Chemistry, 2010. 22(2): p. 1369.

24. Stein, M.L., Interpolation of spatial data: some theory for kriging. 2012: Springer Science \& Business Media.

25. Lauren Rosenshein, L.S., and Monica Pratt. Finding a Meaningful Model. 2011; Available from: https://www.esri.com/news/arcuser/0111/findmodel.html.

26. Jacobs, E.T., et al., Selenium and colorectal adenoma: results of a pooled analysis. J Natl Cancer Inst, 2004. 96(22): p. $1669-75$.

27. Ou, Y., et al., Selenium and colorectal adenomas risk: a meta-analysis. Nutr Cancer, 2012. 64(8): p. 1153-9.

28. Peters, U., et al., High serum selenium and reduced risk of advanced colorectal adenoma in a colorectal cancer early detection program. Cancer Epidemiol Biomarkers Prev, 2006. 15(2): p. 315-20.

29. World Health Organization. 2020.

30. Lener, M.R., et al., Can selenium levels act as a marker of colorectal cancer risk? BMC Cancer, 2013. 13: p. 214.

31. Rahimzadeh, H., et al., Association of Heavy Metals and Selenium Content in Rice with Incidence of Esophageal Cancer in Golestan Province, Iran. Journal of Clinical and Basic Research, 2017. 1(1): p. 27-32.

32. Fernandez-Banares, F., et al., Serum selenium and risk of large size colorectal adenomas in a geographical area with a low selenium status. Am J Gastroenterol, 2002. 97(8): p. 2103-8.

33. Abdolmohammad-Zadeh, H. and E. Ebrahimzadeh, Determination of cobalt in water samples by atomic absorption spectrometry after pre-concentration with a simple ionic liquid-based dispersive liquid-liquid micro-extraction methodology. Central European Journal of Chemistry, 2010. 8(3): p. 617-625.

34. Turkdogan, M.K., et al., Heavy metals in soil, vegetables and fruits in the endemic upper gastrointestinal cancer region of Turkey. Environ Toxicol Pharmacol, 2003. 13(3): p. 175-9. 
35. Lauwerys, R. and D. Lison, Health risks associated with cobalt exposure-an overview. Sci Total Environ, 1994. 150(1-3): p. 1-6.

36. Sauni, R., et al., Cancer incidence among Finnish male cobalt production workers in 1969-2013: a cohort study. BMC Cancer, 2017. 17(1): p. 340.

37. Chen, K., et al., Association of soil arsenic and nickel exposure with cancer mortality rates, a town-scale ecological study in Suzhou, China. Environ Sci Pollut Res Int, 2015. 22(7): p. 5395-404.

38. Peiravi, R., et al., Heavy metals concentrations in Mashhad drinking water network. Zahedan Journal of Research in Medical Sciences, 2013. 15(9): p. 74-6.

39. Kim, M.G., et al., Blood Lead Levels and Cause-Specific Mortality of Inorganic Lead-Exposed Workers in South Korea. PLoS One, 2015. 10(10): p. e0140360.

40. Rehman, K., et al., Prevalence of exposure of heavy metals and their impact on health consequences. J Cell Biochem, 2018. 119(1): p. 157-184.

41. Whanger, P.D., Selenium in the treatment of heavy metal poisoning and chemical carcinogenesis. J Trace Elem Electrolytes Health Dis, 1992. 6(4): p. 209-21.

42. Gatto, N.M., et al., Occupational exposure to hexavalent chromium and cancers of the gastrointestinal tract: a meta-analysis. Cancer Epidemiol, 2010. 34(4): p. 388-99.

43. Halimi, L., et al., Spatial analysis of colorectal cancer incidence in Hamadan Province, Iran: a retrospective cross-sectional study. Applied Spatial Analysis and Policy, 2019: p. 1-11.

44. Sinicrope, F.A., Lynch Syndrome-Associated Colorectal Cancer. N Engl J Med, 2018. 379(8): p. 764-773.

45. Fakheri, H., Z. Bari, and S. Merat, Familial aspects of colorectal cancers in southern littoral of Caspian Sea. Arch Iran Med, 2011. 14(3): p. 175-8.

46. Molaei, M., et al., Colorectal cancer in Iran: immunohistochemical profiles of four mismatch repair proteins. Int J Colorectal Dis, 2010. 25(1): p. 63-9.

47. Zeinalian, M., et al., Epidemioclinical Feature of Early-Onset Colorectal Cancer at-Risk for Lynch Syndrome in Central Iran. Asian Pac J Cancer Prev, 2015. 16(11): p. 4647-52.

\section{Tables}

Table 1. The number of samples in the study area

\begin{tabular}{|llll|}
\hline Required sample size & The area under cultivation (In acres) & Number of milling factories & County name \\
\hline 4 & 2650 & 6 & Bandar gaz \\
\hline 8 & 6408 & 8 & Kordku \\
\hline 4 & 515 & 1 & Bandar torkeman \\
\hline 6 & 4543 & 2 & Agh ghala \\
\hline 7 & 5209 & 18 & Gorgan \\
\hline 6 & 6200 & 7 & Ali Abad \\
\hline 7 & 5275 & 12 & Azadshahr \\
\hline 8 & 6530 & 8 & Gonbad \\
\hline 4 & 1819 & 6 & Ramian \\
\hline 7 & 4985 & 11 & Minoodasht \\
\hline 4 & 970 & 1 & Kalaleh \\
\hline 69 & 45714 & 81 & Total \\
\hline
\end{tabular}

Table 2. The average amount of heavy metals in the counties of Golestan province, Iran, in 2018 


\begin{tabular}{|llllllll|}
\hline County Name & $\mathrm{Zn}(\mathrm{mg} / \mathrm{kg})$ & $\begin{array}{l}\mathrm{Cd} \\
(\mathrm{mg} / \mathrm{kg})\end{array}$ & $\begin{array}{l}\mathrm{Pb} \\
(\mathrm{mg} / \mathrm{kg})\end{array}$ & $\mathrm{Cu}(\mathrm{mg} / \mathrm{kg})$ & $\mathrm{Ni}(\mathrm{mg} / \mathrm{kg})$ & $\begin{array}{l}\mathrm{Co} \\
(\mathrm{mg} / \mathrm{kg})\end{array}$ & $\mathrm{Se}(\mathrm{mg} / \mathrm{kg})$ \\
\hline $\begin{array}{l}\text { Bandar } \\
\text { Torkeman }\end{array}$ & 26.357 & 0 & 0 & 1.0182 & 0.842 & 0 & 2.96 \\
\hline Kordku & 25.579 & 0.0155 & 0.1385 & 1.2265 & 2.8085 & 0.00675 & 1.4234 \\
\hline Bandar Gaz & 32.4563 & 0 & 1.46075 & 1.7875 & 3.90038 & 0.102625 & 2.538 \\
\hline Agh Ghala & 25.6238 & 0 & 0.196833 & 2.3977 & 0.6455 & 0 & 2.73016 \\
\hline Gorgan & 31.3155 & 0.007643 & 1.1145 & 3.0515 & 1.3993 & 0.0185 & 1.1963 \\
\hline Ali Abad & 20.3349 & 0.0085 & 1.7211 & 0.7619 & 3.3621 & 0 & 2.3765 \\
\hline Kalaleh & 26.140125 & 0 & 0.28 & 3.028 & 1.290771 & 0.1005 & 4.7585 \\
\hline Gonbad & 38.7784688 & 0.101688 & 2.235375 & 6.993281 & 4.417125 & 0.110625 & 3.587375 \\
\hline Minoodasht & 54.7726429 & 0 & 1.618571 & 5.633857 & 2.283243 & 0 & 0.494614 \\
\hline Azadshahr & 56.1412857 & 0.073786 & 0.7835 & 10.1745 & 2.577571 & 0 & 1.431738 \\
\hline Ramian & 45.648 & 0 & 1.23575 & 7.62775 & 0.954 & 0 & 2.3255 \\
\hline Range & $20.3349-$ & $0-$ & $0-$ & $0.7619-$ & $0.6455-$ & $0-$ & $0.494614-$ \\
\hline
\end{tabular}

mg: milligrams; kg: kilograms

Table 3. Summary of variables significance for men colon cancer

\begin{tabular}{|llllll|}
\hline Variable & $\begin{array}{l}\text { Significant } \\
{[\%]}\end{array}$ & $\begin{array}{l}\text { Negative } \\
{[\%]}\end{array}$ & $\begin{array}{l}\text { Positive } \\
{[\%]}\end{array}$ & $\begin{array}{l}\text { Coefficient Variable for model } \\
\mathbf{1}\end{array}$ & $\begin{array}{l}\text { Coefficient Variable for model } \\
\mathbf{2}\end{array}$ \\
\hline SE & 20.31 & 100.00 & 0.00 & -6.069037 & -4.614778 \\
\hline CO & 12.50 & 0.00 & 100.00 & 120.329780 & 103.938969 \\
\hline ZN & 9.38 & 71.88 & 28.12 & -0.405843 & - \\
\hline NI & 9.38 & 51.56 & 48.44 & -3.086802 & -3.537392 \\
\hline CD & 6.25 & 25.00 & 75.00 & 80.603505 & 132.584633 \\
\hline CU & 3.12 & 87.50 & 12.50 & - & -1.699960 \\
\hline PB & 0.00 & 39.06 & 60.94 & - & - \\
\hline
\end{tabular}

Table 4. Summary of variables significance for women colon cancer 


\begin{tabular}{|llllll|}
\hline Variable & $\begin{array}{l}\text { Significant } \\
{[\%]}\end{array}$ & $\begin{array}{l}\text { Negative } \\
{[\%]}\end{array}$ & $\begin{array}{l}\text { Positive } \\
{[\%]}\end{array}$ & $\begin{array}{l}\text { Coefficient Variable for model } \\
\mathbf{1}\end{array}$ & $\begin{array}{l}\text { Coefficient Variable for model } \\
\mathbf{2}\end{array}$ \\
\hline ZN & 3.12 & 93.75 & 6.25 & -0.181621 & -0.170447 \\
\hline CO & 1.56 & 4.69 & 95.31 & 55.023949 & 29.755027 \\
\hline SE & 1.56 & 100.00 & 0.00 & -2.558817 & -1.807687 \\
\hline CD & 0.00 & 35.94 & 64.06 & - & - \\
\hline PB & 0.00 & 21.88 & 78.12 & - & - \\
\hline CU & 0.00 & 81.25 & 18.75 & - & - \\
\hline NI & 0.00 & 79.69 & 20.31 & -0.991396 & - \\
\hline
\end{tabular}

Table 5. Highest Adjusted $\mathrm{R}^{2}$ Results for male colon cancer

\begin{tabular}{|c|c|c|c|c|c|c|c|c|c|c|c|}
\hline id & Explora & ry Regr & sion $\mathrm{M}$ & & & $\operatorname{Adj} R^{2}$ & $\mathrm{AlCc}$ & $J B$ & $\mathrm{~K}(\mathrm{BP})$ & VIF & SA \\
\hline 1 & $\bar{Z} \mathrm{ZN}^{\star \star \star *}$ & $+C D^{\star *}$ & $-\mathrm{NI} \mathrm{I}^{\star \star}$ & $+\mathrm{CO} * * *$ & $\bar{S} E^{\star \star \star}$ & 0.769988 & 89.139950 & 0.994852 & 0.300309 & 4.262827 & 0.544661 \\
\hline 2 & $\bar{C}$ & $+C D^{\star *}$ & $\left.\overline{\mathrm{N}}\right|^{\star \star}$ & $+\mathrm{CO} * \star$ & $\bar{S} E^{\star \star \star}$ & 0.722625 & 91.199583 & 0.833018 & 0.416308 & 3.715638 & 0.308703 \\
\hline
\end{tabular}

AdjR2: Adjusted R-Squared; AICc: Akaike's Information Criterion; JB: Jarque-Bera p-value; K(BP): Koenker (BP) Statistic p-value; VIF: Max Variance Inflation Factor; SA: Global Moran's I p-value; Model Variable sign: (+/-); Variable significance $(*=0.10 ; * \star=0.05 ; * \star *=$ 0.01).

Table 6. Highest Adjusted $\mathrm{R}^{2}$ Results for female colon cancer

\begin{tabular}{|c|c|c|c|c|c|c|c|c|c|c|c|}
\hline id & Explo & tory Reg & ession & del & & $\operatorname{Adj}^{2}$ & $\mathrm{AlCc}$ & $\mathrm{JB}$ & $\mathrm{K}(\mathrm{BP})$ & VIF & SA \\
\hline 1 & $-Z N^{\star *}$ & $-\mathrm{NI}^{*}$ & $+\mathrm{CO} * *$ & $-S E^{\star \star}$ & - & 0.31 & 93.09 & 0.59 & 0.10 & 4.26 & 0.89 \\
\hline 2 & $-Z N^{\star \star}$ & $+\mathrm{CO} *$ & -SE* & - & - & 0.30 & 127.32 & 0.81 & 0.43 & 4.66 & 0.48 \\
\hline
\end{tabular}

$\mathrm{AdjR}^{2}$ : Adjusted R-Squared; AICc: Akaike's Information Criterion; JB: Jarque-Bera p-value; K(BP): Koenker (BP) Statistic p-value; VIF: Max Variance Inflation Factor; SA: Global Moran's I p-value; Model Variable sign: (+/-); Variable significance $\left(^{*}=0.10 ;{ }^{* *}=0.05 ;{ }^{* \star *}=\right.$ 0.01).

Figures 


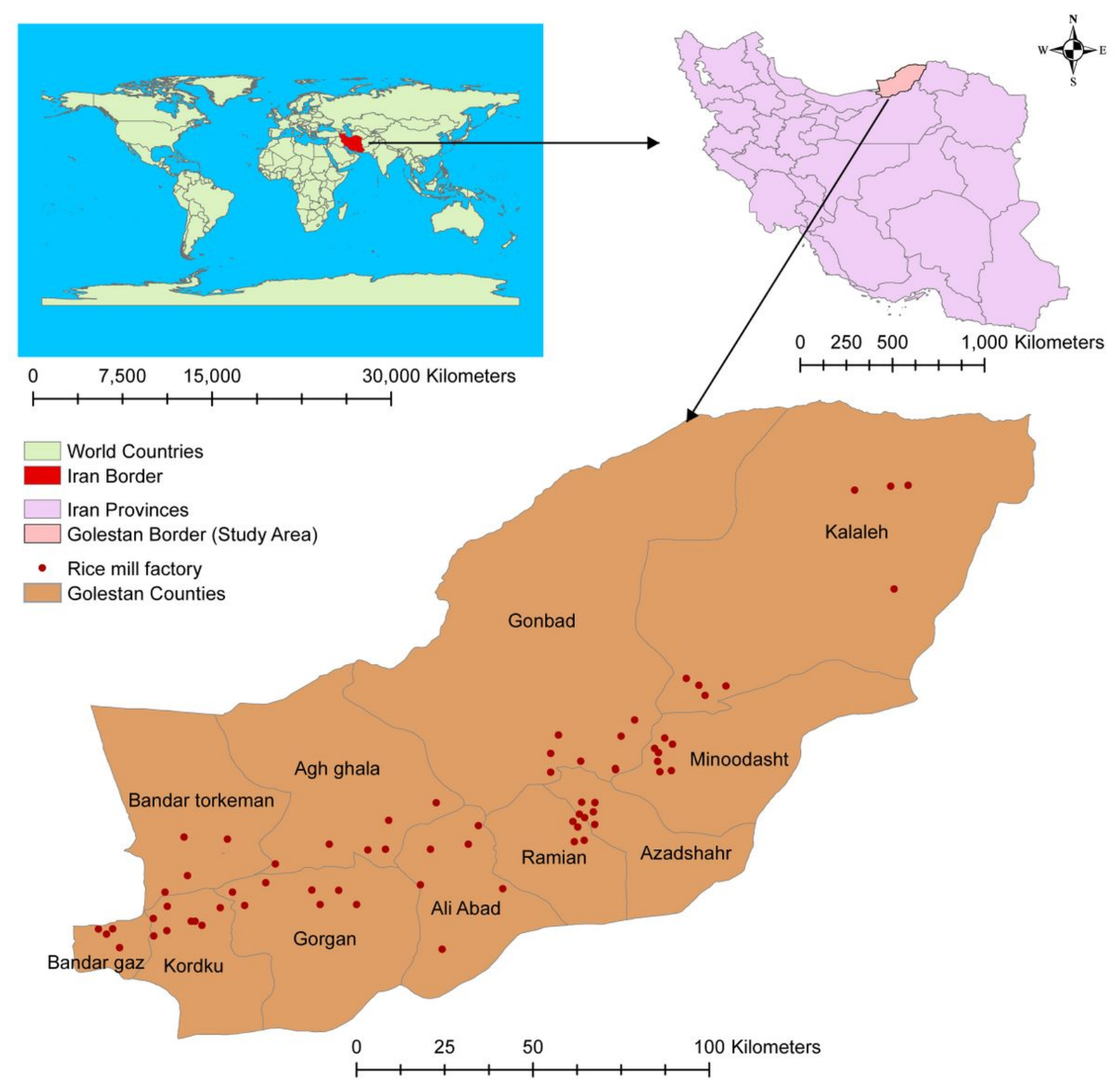

\section{Figure 1}

The location of the study area with the distribution of milling factories in 2018. Note: The designations employed and the presentation of the material on this map do not imply the expression of any opinion whatsoever on the part of Research Square concerning the legal status of any country, territory, city or area or of its authorities, or concerning the delimitation of its frontiers or boundaries. This map has been provided by the authors. 


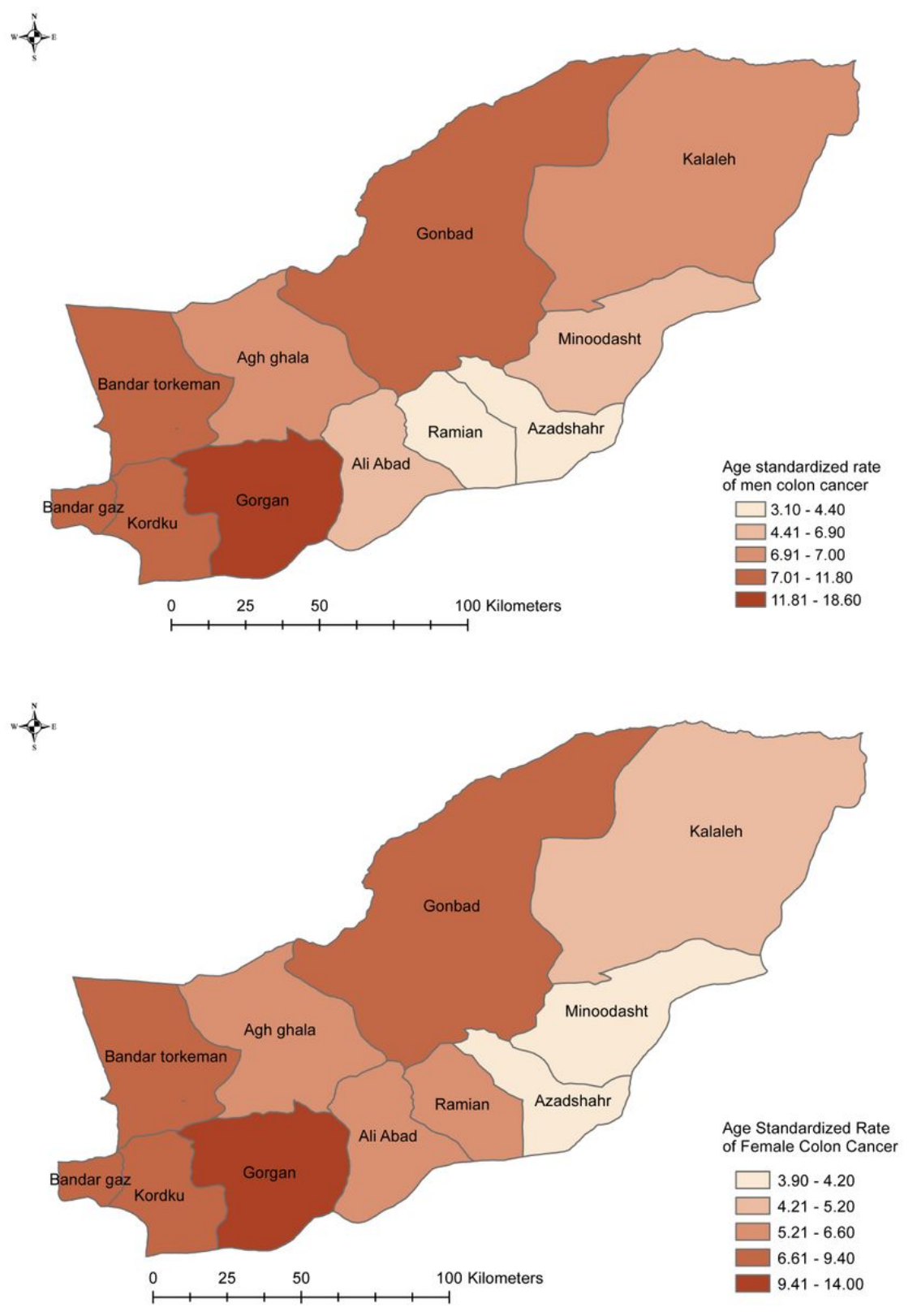

\section{Figure 2}

The geographical distribution of age-standardized colon cancer rate in the study area. Note: The designations employed and the presentation of the material on this map do not imply the expression of any opinion whatsoever on the part of Research Square concerning the legal status of any country, territory, city or area or of its authorities, or concerning the delimitation of its frontiers or boundaries. This map has been provided by the authors. 

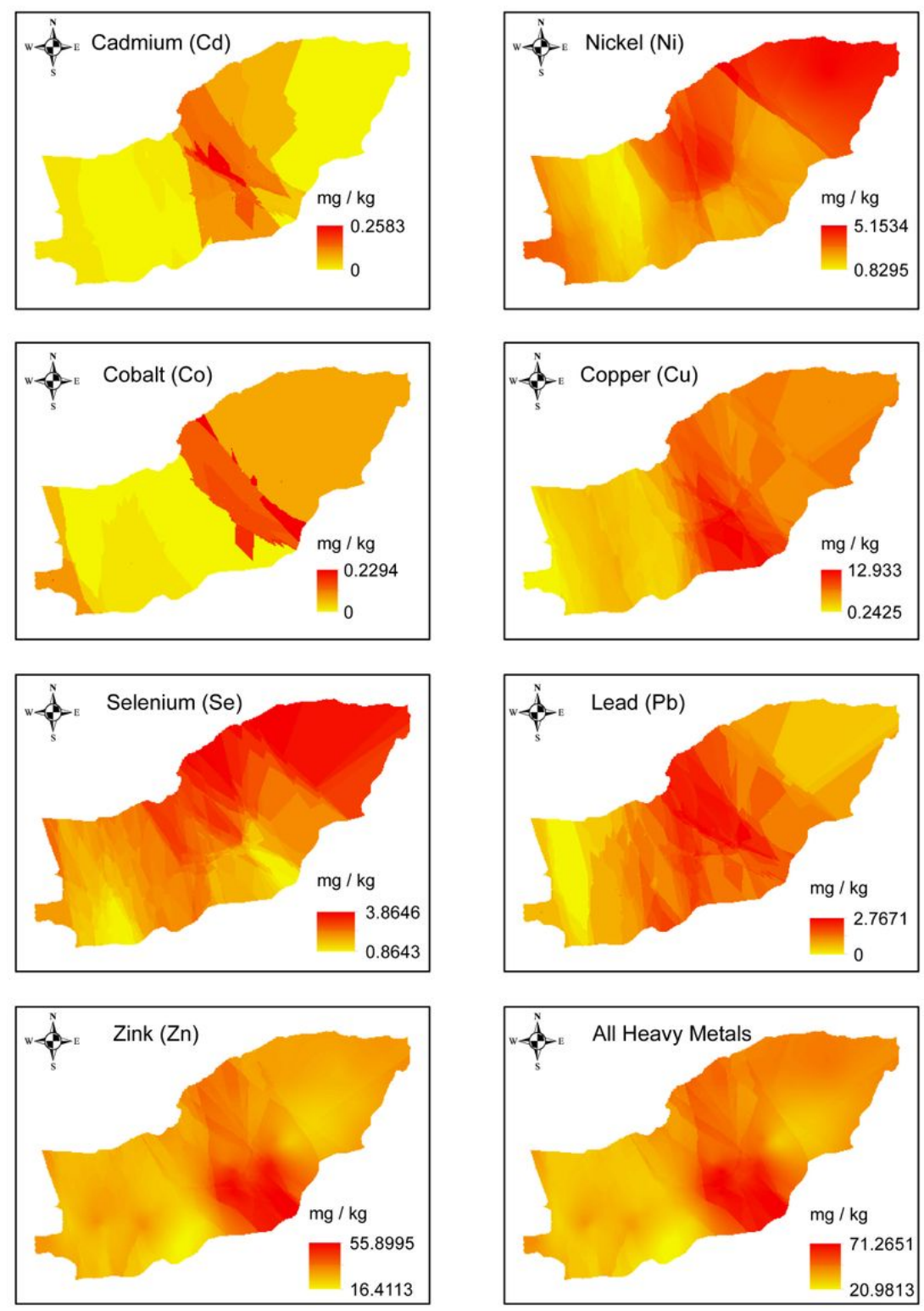

0 $65 \quad 130$ 260 Kilometers

\section{Figure 3}

The spatial density of explanatory variables used for the exploratory regression model. Note: The designations employed and the presentation of the material on this map do not imply the expression of any opinion whatsoever on the part of Research Square concerning the legal status of any country, territory, city or area or of its authorities, or concerning the delimitation of its frontiers or boundaries. This map has been provided by the authors. 